\title{
Comparison of Optimised MDI versus Pumps with or without Sensors in Severe Hypoglycaemia (the Hypo COMPaSS trial)
}

\author{
Stuart Little ${ }^{1}$, Thomas Chadwick², Pratik Choudhary ${ }^{3}$, Cath Brennand ${ }^{2}$, Julia Stickland², Shalleen Barendse ${ }^{4}$, \\ Tolulope Olateju ${ }^{5}$, Lalantha Leelarathna ${ }^{6}$, Emma Walkinshaw ${ }^{7}$, Horng K Tan ${ }^{8}$, Sally M Marshall ${ }^{1}$, Reena M Thomas ${ }^{1}$, \\ Simon Heller ${ }^{7}$, Mark Evans ${ }^{6}$, David Kerr ${ }^{5}$, Daniel Flanagan ${ }^{8}$, Jane Speight ${ }^{4,9,10}$ and James AM Shaw ${ }^{7^{*}}$
}

\begin{abstract}
Background: Severe hypoglycaemia (SH) is one of the most feared complications of type 1 diabetes (T1DM) with a reported prevalence of nearly 40\%. In randomized trials of Multiple Daily Injections (MDI) and Continuous Subcutaneous Insulin Infusion (CSII) therapy there is a possible benefit of CSII in reducing SH. However few trials have used basal insulin analogues as the basal insulin in the MDI group and individuals with established SH have often been excluded from prospective studies. In published studies investigating the effect of Real Time Continuous Glucose Monitoring (RT-CGM) benefit in terms of reduced SH has not yet been demonstrated. The primary objective of this study is to elucidate whether in people with T1DM complicated by impaired awareness of hypoglycaemia $(\mathrm{IAH})$, rigorous prevention of biochemical hypoglycaemia using optimized existing self-management technology and educational support will restore awareness and reduce risk of recurrent $\mathrm{SH}$.
\end{abstract}

Methods/design: This is a multicentre prospective RCT comparing hypoglycaemia avoidance with optimized MDI and CSII with or without RT-CGM in a $2 \times 2$ factorial design in people with type 1 diabetes who have IAH. The primary outcome measure for this study is the difference in IAH (Gold score) at 24 weeks. Secondary outcomes include biomedical measures such as HbA1c, SH incidence, blinded CGM analysis, self monitored blood glucose (SMBG) and response to hypoglycaemia in gold standard clamp studies. Psychosocial measures including well-being and quality of life will also be assessed using several validated and novel measures. Analysis will be on an intention-to-treat basis.

Discussion: Most existing RCTs using this study's interventions have been powered for change in $\mathrm{HbA1c}$ rather than IAH or SH. This trial will demonstrate whether IAH can be reversed and SH prevented in people with T1DM in even those at highest risk by using optimized conventional management and existing technology.

Trial Registration: ISRCTN52164803 Eudract No: 2009-015396-27

\section{Background}

Type 1 diabetes mellitus (T1DM) accounts for $5-10 \%$ [1] of those with diabetes and is characterised by an absolute deficiency of insulin caused by immunologically mediated damage to the beta-cells in the pancreas. Onset can occur at any age but is most commonly in children, adolescents and young adults. Complications

\footnotetext{
* Correspondence: jim.shaw@ncl.ac.uk

${ }^{1}$ Institute of Cellular Medicine, The Medical School, Newcastle University, 4th Floor William Leech Building, Framlington Place, Newcastle upon Tyne NE2 $4 \mathrm{HH}, \mathrm{UK}$

Full list of author information is available at the end of the article
}

include microvascular disease of the kidneys, eyes and nervous tissue in addition to macrovasular disease such as ischaemic heart disease, cerebrovascular disease and peripheral vascular disease.

As there is no cure for T1DM, management entails regulation of blood glucose levels with insulin replacement therapy and dietary modification. There is incontrovertible evidence from the landmark DCCT [2] and the follow-up EDIC [3] study that microvascular and macrovascular complications can be prevented by rigorous avoidance of high glucose levels.

\section{Biomed Central}

(c) 2012 Little et al.; licensee BioMed Central Ltd. This is an Open Access article distributed under the terms of the Creative Commons Attribution License (http://creativecommons.org/licenses/by/2.0), which permits unrestricted use, distribution, and reproduction in any medium, provided the original work is properly cited. 
Despite 90 years' clinical experience with insulin replacement therapy, however, severe hypoglycaemia $(\mathrm{SH})$ remains the major factor limiting optimal glycaemic control [4]. In a retrospective epidemiological survey of an unselected population with T1DM the prevalence of $\mathrm{SH}$ was reported to be $37 \%$ over a one year recall period [5]. $\mathrm{SH}$ remains one of the most feared complications of insulin therapy as it can result in collapse without warning, fits, or even sudden death [6,7]. Tight glycaemic control in the DCCT attained by MDI (multiple daily injections) or CSII (continuous subcutaneous insulin infusion) was associated with a three-fold increase in SH [2].

Established risk factors for $\mathrm{SH}$ include age, duration of diabetes, tight glycaemic control, previous $\mathrm{SH}$ and impaired awareness of hypoglycaemia (IAH) [8]. IAH occurs in $20 \%$ of those with T1DM and is characterised by diminished autonomic warning symptoms of impending hypoglycaemia and associated with a six-fold increased risk of $\mathrm{SH}$ [9-11]. Antecedent biochemical hypoglycaemia $(\mathrm{BH})$ including silent nocturnal hypoglycaemia can induce IAH in addition to diminished counter-regulatory hormone response in people with established diabetes [12].

In insulinoma patients, surgical resection restores normal symptomatic and neuroendocrine response to hypoglycaemia providing further evidence of the direct causative role of $\mathrm{BH}$ in IAH and $\mathrm{SH}$ [13]. Rigorous avoidance of hypoglycaemia by relaxing glycaemic targets while maintaining conventional MDI therapy has been shown to restore hypoglycaemia awareness with normalisation of glycaemic thresholds for symptoms and neuroendocrine responses during a stepped hyperinsulinemic-hypoglycaemic clamp study $[14,15]$. This was, however, associated with a $0.4-1.1 \%(4-12 \mathrm{mmol} /$ mol) increase in $\mathrm{HbA}_{1 \mathrm{c}}$. Moreover, success has previously been confined to those with relatively short duration of diabetes [7] or transiently following a brief period of absolute hypoglycaemia avoidance in those with longer duration diabetes [8].

The potential for reducing nocturnal and late postprandial hypoglycaemia by employing rapid-acting insulin analogues pre-prandially has been demonstrated [16-18]. In addition, reduced nocturnal hypoglycaemia has been reported in insulin glargine trials [19-23] and insulin detemir trials [24-27]. However, individuals with a previous history of IAH and $\mathrm{SH}$ and longer duration of diabetes have typically been excluded from randomized clinical trials investigating insulin analogues. The National Institute for Health and Clinical Excellence (NICE) in the UK has recommended further studies to assess the impact of insulin analogues on duration and severity of hypoglycaemia and on quality of life (QoL) [28].

In randomized trials of CSII versus MDI, a relatively modest improvement in $\mathrm{HbA}_{1 \mathrm{c}}$ has been demonstrated in addition to the potential for reduction in the incidence of $\mathrm{SH}[29,30]$. There have been relatively few trials to date with glargine as the basal insulin in the MDI comparator group [30,31]. A Cochrane review has indicated a possible benefit of CSII as compared to MDI in reducing $\mathrm{SH}$ but data also indicated no benefit of CSII in reducing non-severe hypoglycaemic events [32]. Individuals with established SH have again often been excluded from prospective studies, despite a reported sustained reduction in the incidence of $\mathrm{SH}$ in a non-randomized, retrospective study [33]. NICE recommends CSII therapy where achievement of optimal glycaemic control has been precluded by disabling hypoglycaemia but has emphasized the absence of studies in high-risk individuals together with the need for randomized control trials to assess biomedical and psychosocial outcomes of both analogue MDI and CSII in those with established SH [34].

The potential role of real time continuous glucose monitoring (RT-CGM) has generated considerable interest among clinicians and those with T1DM since its introduction. Improved overall glycaemic control has been reported, though benefit in terms of reduced $\mathrm{SH}$ has not yet been demonstrated [35,36]. Studies that have compared RT-CGM integrated with CSII with analogue regimens have also failed to demonstrate a difference in rates of $\mathrm{SH}$ although they have suggested reduced HbA1c with the technology $[37,38]$. There is evidence that RT-CGM can significantly reduce the time spent with a blood glucose $<3.5 \mathrm{mmol} / \mathrm{l}$ [39], however there is no evidence from the major RCTs published that it can prevent SH. This may be due to the study design and participant selection criteria of these trials. Sustained avoidance of BH achieved through feedback from RT-CGM use with the aim of restoring hypoglycaemia awareness and preventing risk of further $\mathrm{SH}$ in high-risk individuals with T1DM has not been assessed.

Despite implicit acknowledgement amongst healthcare professionals that $\mathrm{SH}$ impairs an individual's QoL, there is little formal evidence for this in the literature. Davis et al., have demonstrated the major impact of $\mathrm{SH}$ on perceived health and well being [40] but the full impact of $\mathrm{SH}$ on QoL has not been assessed adequately. Relatively few studies have directly assessed impact of successful prevention of further $\mathrm{SH}$ in addition to differential effects according to therapeutic intervention.

We have previously conducted a 6-month randomised prospective pilot study in individuals with T1DM complicated by $\mathrm{SH}$, comparing rigorous $\mathrm{BH}$ avoidance with optimised analogue MDI; CSII; or education alone (EDUC) [41]. This demonstrated absolute prevention of recurrent $\mathrm{SH}$ in $71 \%$ in all groups. Quantitative improvement in IAH was confirmed using the validated Clarke questionnaire [42] in addition to restored symptomatic response to clamp-induced hypoglycaemia. Concomitant improvement in glycaemic control (HbA1c) was achieved with MDI 
(baseline: $8.6 \pm 1.1 \%$, endpoint: $7.6 \pm 0.7 \%, \mathrm{p}=0.04$ ) and CSII (baseline: $8.5 \pm 1.9 \%$, endpoint: $7.4 \pm 1.0 \%, \mathrm{p}=0.06$ ) but not EDUC (baseline: $8.5 \pm 1.1 \%$, endpoint: $8.3 \pm 1.0 \%$, $\mathrm{p}=0.54$ ). Significant improvements in diabetes-specific QoL and fear of hypoglycaemia were also demonstrated in MDI and CSII groups. Although in this study RT-CGM was not used, these pilot data provide the rationale, robust power calculation and proven study design for a definitive RCT, without the requirement for an education alone arm.

\section{Study objectives \\ Primary objective}

- To demonstrate that by optimising conventional management, including the use of real time continuous glucose monitoring (RT-CGM), in individuals with T1DM complicated by IAH, rigorous prevention of $\mathrm{BH}$ will restore awareness and reduce risk of recurrent $\mathrm{SH}$.

\section{Secondary objectives}

- To quantify and compare BH identified by selfmonitored blood glucose (SMBG) and blinded CGM profiles during each intervention.

- To quantify and compare overall glycaemic control and glucose lability in each group by analysis of HbA1c, SMBG and blinded CGM.

- To quantify and compare total daily doses of insulin before and after the intervention period.

- To compare health utility, well-being and QoL during each intervention using validated and novel measures.

- To perform secondary analyses of those who continue to experience IAH regardless of study intervention, to determine factors associated with absence of response. It is hypothesised that these will include two sub-groups: one in whom an absolute focus on avoidance of high glucose (evidenced from patientreported outcome (PRO) measures) leads to continued biochemical hypoglycaemia despite the study goals; and a second with severe autonomic neuropathy (evidenced from clinical history) who are unable to recover autonomic warning symptoms of hypoglycaemia despite effective reduction in biochemical hypoglycaemia.

- To determine symptomatic, counter-regulatory hormone and cognitive response to hypoglycaemia in gold standard clamp studies. Comparisons will be made between those randomised to CSII and those randomised to $\mathrm{MDI}$; in addition to RT-CGM versus no RT-CGM; and responders with restored hypoglycaemia awareness versus non-responders with persistent IAH despite study intervention.

\section{Methods/design}

\section{Ethical and governance approval}

Ethical approval for this study has been granted by Sunderland Research Ethics Committee (09/H0904/63) and Clinical Trial Authorisation has been given by the Medicines and Healthcare products Regulatory Agency (17136/0246/001-0001). Site Specific Approval has been granted by all participating Acute Hospital Trust Research and Development Departments.

\section{Study design}

The study is an interventional multicentre prospective RCT comparing hypoglycaemia avoidance with optimised subcutaneous insulin analogue regimen (MDI) and insulin pump therapy (CSII) with or without adjunctive RT-CGM in a $2 \times 2$ factorial design (Figure 1). The trial design is consistent with the CONSORT Statement [43].

\section{Participants}

Participants will be recruited from the diabetes clinics of the five participating UK tertiary referral and academic hypoglycaemia/CSII centres (Royal Bournemouth Hospital, Bournemouth; Addenbrooke's Hospital, Cambridge; Newcastle Diabetes Centre, Newcastle upon Tyne, UK; Derriford Hospital, Plymouth; Northern General Hospital, Sheffield). Patients with T1DM, a history of IAH and increased risk of SH will be assessed to determine if they are eligible for the study. It is envisaged that the majority of these will have experienced $\mathrm{SH}$ within the preceding year, although this is not mandatory for study participation. Those who are considered potentially eligible will be approached to give their written informed consent before attending for a screening visit at which inclusion criteria will be checked.

\section{Inclusion criteria}

Individuals who are aged 18-74 years and have a diagnosis of diabetes mellitus according to ADA [44] / WHO [45] criteria and consistent with a clinical diagnosis of T1DM. Participants will have:

- serum C-peptide below the quality assured limit of detection for the assay and laboratory $(<50 \mathrm{pmol} / \mathrm{L})$ with simultaneous exclusion of $\mathrm{BH}$ (glucose $<4.0 \mathrm{mmol} / \mathrm{l}$ ) by laboratory plasma glucose assay.

- impaired awareness of hypoglycaemia, as confirmed by a Gold score $\geq 4$ [ [11].

\section{Exclusion criteria}

- Any condition that in the investigator's judgement is likely to cause the participant to be unable to understand the information in the Informed Consent Document or to provide informed consent. 


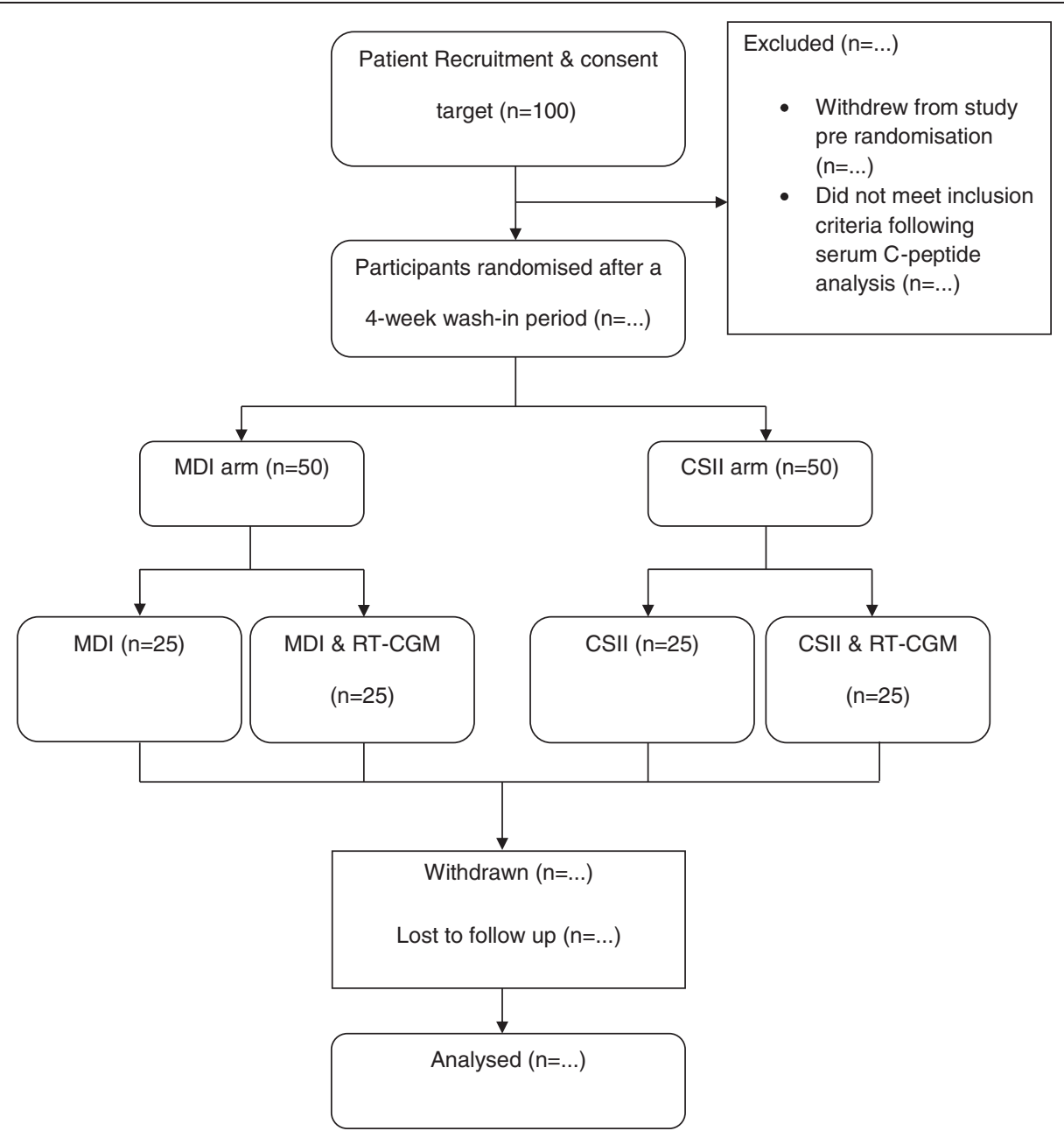

CSII: Continuous Subcutaneous Insulin Infusion

MDI: Multiple Daily Injections

RT-CGM: Real-Time Continuous Glucose Monitoring

Figure 1 Proposed flow through RCT.

- Insufficient proficiency in English, below that to enable the participant to understand both verbal and written information during the study. This is due to the complexity of the education programme, the need for independent completion of the questionnaire measures, and the degree of communication required between participants and clinicians during the study.

- Unwilling to undertake intensive insulin therapy, including randomisation to use of CSII, optimised MDI regimen or RT-CGM.

- Unwilling to undertake glucose profiles using the subcutaneous continuous glucose monitoring (CGM) equipment.

- Unwilling to use SMBG at least 4 times daily.
- Unwilling to monitor and record signs and symptoms of hypoglycaemia.

- A history of intolerance to insulin glargine.

Trial intervention and study procedures

Schedule for study visits is given in Table 1.

\section{Four week baseline period}

After consent, participants will undertake a 4-week washin period before the 24-week RCT period. Participants will be educated in the use of the study-specific prospective SMBG hypoglycaemia diary. All participants will be provided with a study hand-held glucometer (Contour link ${ }^{\circledR}$, Bayer Healthcare) to measure daily 4-point and weekly 8-point profiles. They will be asked to record clinical 
Table 1 Visit schedule

\begin{tabular}{|c|c|c|c|c|c|c|c|c|c|c|c|c|c|c|c|c|c|c|c|c|c|c|c|c|c|c|}
\hline \multirow{2}{*}{$\begin{array}{l}\text { Study period } \\
\text { Visit number }\end{array}$} & \multicolumn{3}{|c|}{$\begin{array}{l}4 \text { week } \\
\text { wash in } \\
\text { period }\end{array}$} & \multicolumn{17}{|c|}{24 week primary $\mathrm{RCT}$} & \multicolumn{6}{|c|}{$\begin{array}{c}18 \text { month RT-CGM RCT } \\
\text { continuation }\end{array}$} \\
\hline & 1 & 2 & 3 & 4 & 5 & 67 & 78 & 9 & 10 & 11 & 12 & 13 & 14 & 15 & 16 & 17 & 18 & 19 & 20 & 21 & 22 & 23 & 24 & 25 & 26 & 27 \\
\hline informed consent & $x$ & & & & & & & & & & & & & & & & & & & & & & & & & \\
\hline eligibility criteria & $x$ & & & & & & & & & & & & & & & & & & & & & & & & & \\
\hline $\begin{array}{l}\text { given information sheet on clamp } \\
\text { study }\end{array}$ & $x$ & & & & & & & & & & & & & & & & & $x$ & & & & & & & & \\
\hline $\begin{array}{l}\text { hypoglycaemia screening } \\
\text { questionnaire }\end{array}$ & $x$ & & $x$ & & & & & & & & & & & & & & & & & & & & & & & \\
\hline $\mathrm{HbA} 1 \mathrm{c}$ & $x$ & & $x$ & & & & & & $x$ & & $x$ & & $x$ & & $x$ & & $x$ & & $x$ & & & $x$ & & $x$ & & $x$ \\
\hline C-peptide and plasma glucose & $x$ & & & & & & & & & & & & & & & & & & & & & & & & & \\
\hline retinal photographs & & $x$ & & & & & & & & & & & & & & & & & & & & & & & & \\
\hline urine albumin:creatinine ratio & & $x$ & & & & & & & & & & & & & & & & & & & & & & & & \\
\hline demographic info & & & $x$ & & & & & & & & & & & & & & & & & & & & & & & \\
\hline concomitant medication & & & $x$ & & & & & & $x$ & & $x$ & & $x$ & & $x$ & & $x$ & & $x$ & & & $x$ & & $x$ & & $x$ \\
\hline full physical examination & & & $x$ & & & & & & & & & & & & & & & & $x$ & & & & & & & \\
\hline history of glycaemic control & & & & & & & & & $x$ & & $x$ & & $x$ & & $x$ & & $x$ & & & & & & & & & \\
\hline $\begin{array}{l}\text { full medical history including } \\
\text { glycaemic control }\end{array}$ & & & $x$ & & & & & & & & & & & & & & & & $x$ & & & $x$ & & $x$ & & $x$ \\
\hline vital signs & & & $x$ & & & & & & $x$ & & $x$ & & $x$ & & $x$ & & $x$ & & $x$ & & & $x$ & & $x$ & & $x$ \\
\hline height & & & $x$ & & & & & & & & & & & & & & & & & & & & & & & \\
\hline weight & & & $x$ & & & & & & $x$ & & $x$ & & $x$ & & $x$ & & $x$ & & $x$ & & & $x$ & & $x$ & & $x$ \\
\hline TFTs & & & & & $x$ & & & & & & & & & & & & & & & & & & & & & \\
\hline Coeliac antibody & & & & & $x$ & & & & & & & & & & & & & & & & & & & & & \\
\hline short synacthen test & & & & & $x$ & & & & & & & & & & & & & & & & & & & & & \\
\hline detailed SH history & & & $x$ & & & & & & $x$ & & $x$ & & $x$ & & $x$ & & $x$ & & $x$ & & & $x$ & & $x$ & & $x$ \\
\hline Modified Clarke/Edinburgh & & & $x$ & & & & & & & & & & & & & & & & $x$ & & & $x$ & & $x$ & & $x$ \\
\hline QoL questionnaires & & & $x$ & & & & & & & & & & & & & & & & $x$ & & & $x$ & & $x$ & & $x$ \\
\hline week 4 short questionnaire pack & & & & & & & & & $x$ & & & & & & & & & & & & & & & & & \\
\hline 4 week Blood Glucose / hypo diary & $x$ & & $x$ & & & & & & $x$ & & $x$ & & $x$ & & $x$ & & $x$ & & $x$ & & & & & & & \\
\hline 7 day CGMS placement & & $x$ & & & & & & $x$ & & $x$ & & $x$ & & $x$ & & $x$ & & $x$ & & & $x$ & & $x$ & & $x$ & \\
\hline Autonomic function tests & & & & $x$ & & & & & & & & & & & & & & & & $x$ & & & & & & \\
\hline clamp study & & & $x$ & & & & & & & & & & & & & & & $x$ & & & & & & & & \\
\hline education programme & & & & & & $x$ & & & & & & & & & & & & & & & & & & & & \\
\hline $\begin{array}{l}\text { Insulin administration education } \\
\text { session }\end{array}$ & & & & & & & $x$ & & & & & & & & & & & & & & & & & & & \\
\hline $\begin{array}{l}\text { Home glucose monitoring/RT } \\
\text { education session }\end{array}$ & & & & & & & $x$ & & & & & & & & & & & & & & & & & & & \\
\hline
\end{tabular}

details of all glucose levels $<4 \mathrm{mmol} / \mathrm{l}$ and symptomatic hypoglycaemic events. All participants will wear a blinded CGM device (iPro ${ }^{\mathrm{TM}} 1$, Medtronic) for 7 days during the baseline period.

At the end of the wash-in period, participants will attend for a baseline study visit where the investigator will complete the GCP-compliant baseline Case Report Form (CRF). This will record demographic information, full diabetes-specific clinical history including frequency and consequences of $\mathrm{SH}$ events over the preceding 12 months and full clinical examination assessing complication status. The study SMBG / hypoglycaemia diary will be collected and CGM device downloaded. In addition, hypoglycaemia awareness will be re-evaluated using the validated Gold Score [11] and Clarke questionnaire [42].

A first morning urine sample for albumin: creatinine ratio will be collected together with dilated retinal photography if not performed within the preceding 6 months. A 
blood sample will be taken for HbA1c (DCCT-aligned), urea and electrolytes, liver function tests and lipid profile analysed at local site quality-assured clinical laboratory. Study-specific PRO questionnaire booklets will be completed comprising several validated and novel measures. During design of and preparation for the study, new measures were developed by the team to capture aspects of participant experience for which validated measures did not exist (e.g. hypoglycaemia cues) or where there was specific concern that existing measures were insensitive (e.g. the Gold and the Clarke have been demonstrated to lack sensitivity to improvements in awareness). All PRO measures included in the evaluation are listed in Table 2.

\section{Baseline hypoglycaemic clamp study}

A stepped hyperinsulinaemic hypoglycaemic clamp study will be conducted at baseline and at 24 weeks with participants who are willing to undergo this procedure for which specific consent will be sought separately. It is envisaged that approximately $25 \%$ of participants will be studied. The method is described in detail later.

\section{Autonomic function testing}

Before the start of the RCT, participants will attend for non-invasive detailed cardiac autonomic function testing using the recommendations in the review by Tesfaye et al. [46]. These will include heart rate response to deep breathing, a Valsalva maneuver and heart rate and blood pressure response to standing interpreted using age normative values. Spectral analysis of heart rate variability and assessment of cardiac vagal baroreflex sensitivity (BRS) will be carried out over a five minute period of controlled breathing. Structured assessment of global autonomic function will be made using the Autonomic Symptom Profile Questionnaire [47].

\section{Concomitant autoimmune disease screening}

Participants will attend for a short synacthen test to screen for adrenocortical insufficiency. At this visit a sample will also be taken for serum thyroid stimulating hormone assay to exclude thyroid disease and for anti-endomysial antibody analysis to exclude coeliac disease. New diagnoses of other autoimmune diseases will not preclude participation in the study. If indicated participants with newly diagnosed autoimmune disease will be referred to an appropriate specialist for further investigation and management.

\section{Education visit}

Following experience in the pilot study [41] and informed by insights from the qualitative study undertaken in preparation for the RCT (paper submitted), a brief education programme (with formal curriculum and workbook, referred to as the 'My Hypo COMPaSS' tool), was developed. Participants will attend a brief education session (approximately $3 \mathrm{~h}$ ) individually or in small groups of up to four. During the session, a trained research fellow, specialist nurse or dietician will facilitate discussions and exercises targeted specifically at rigorous avoidance of $\mathrm{BH}$ while maintaining overall glycaemic control [48], including four key elements forming the four points of the 'Hypo COMPaSS' establishing the imperatives: to never delay the treatment of hypoglycaemia and the optimal treatments for hypoglycaemia; to recognise the individual's unique times of increased risk; to recognise hypoglycaemia by the presence of subtle symptoms; to be particularly careful about detecting and preventing nocturnal hypoglycaemia. Also included will be advice on self-adjustment of insulin doses according to carbohydrate intake, SMBG and planned activity and recommendation for oral carbohydrate administration for all glucose levels less than $4 \mathrm{mmol} / \mathrm{l}$.

\section{Table 2 Validated and novel patient reported outcome measures assessed during the Hypo COMPaSS trial}

\begin{tabular}{|c|c|}
\hline Validated PRO measures & Novel PRO measures undergoing validation \\
\hline - The Gold Score [44] & - The Hypoglycaemia Awareness Questionnaire (HypoA-Q)* \\
\hline - The Edinburgh Hypoglycaemia Survey [54] & \multirow{2}{*}{$\begin{array}{l}\text { - The Hypoglycaemia Burden Questionnaire (HypoB-Q)* - } \\
\text { part A only }\end{array}$} \\
\hline - Clarke Hypoglycaemia Awareness Questionnaire (minimally modified version) & \\
\hline • The Hypoglycaemia Fear Survey II (HFS II) [55] & - The Hypoglycaemia Cues Questionnaires (HypoC-Q)* \\
\hline • The Hyperglycaemia Avoidance Scale [56] & - The Blood Glucose Monitoring Questionnaire (BGM-Q)* \\
\hline - The Diabetes Treatment Satisfaction Questionnaire - status version (DTSQ(s)) [57] & $\begin{array}{l}\text { - The Quality of Life Questionnaire Diabetes (QoL-Q } \\
\text { Diabetes)^ }\end{array}$ \\
\hline $\begin{array}{l}\text { - Insulin Treatment Satisfaction Questionnaire [58] - abridged version including two } \\
\text { subscales only }\end{array}$ & - The Attitudes to Awareness of Hypos Questionnaire\# \\
\hline \multicolumn{2}{|l|}{ • EuroQoL EQ-5D [59] } \\
\hline - Perceived Control of Diabetes scales (type 1) [60] & \\
\hline
\end{tabular}

* designed by Prof Jane Speight and Dr Shalleen Barendse (৫ AHP Research, 2010).

$\wedge$ designed by Prof Jane Speight, Dr Alison Woodcock and Matthew Reaney (๑ AHP Research, 2007).

\# designed by Dr Nicole DeSoyza, Helen Rogers and Prof Stephanie Amiel (King's College London). 


\section{Intervention period \\ Randomisation}

Participants will be allocated by third party concealed randomisation by centre and baseline HbA1c (with stratification cut-off of $64 \mathrm{mmol} / \mathrm{mol}(8 \%)$ to one of four groups for a period of 24 weeks):

- MDI with SMBG (group 1; $\mathrm{n}=25$ ).

- MDI with SMBG and RT-CGM (group 2; n = 25).

- CSII with SMBG (group 3; n = 25).

- CSII with SMBG and RT-CGM (group 4; n = 25).

As this is an open study it is not possible for participants to be blinded to study treatment arm. Randomisation will be administered centrally by Newcastle Clinical Trial Unit (NCTU) using a secure web based system.

\section{Study Interventions}

The primary goal of titration throughout the 24-week RCT period will be the absolute avoidance of all glucose levels $<4 \mathrm{mmol} / \mathrm{l}$ as determined by CGM and SMBG. This will be achieved by setting ' 4 as the floor' with all glucose levels $<4 \mathrm{mmol} / \mathrm{l}$ treated by $15 \mathrm{~g}$ glucose with repeat SMBG every $15 \mathrm{~min}$ until glucose $>4 \mathrm{mmol} / \mathrm{l}$, in addition to consideration of insulin dose reduction.

The trial is designed to prevent any potential bias from additional educational support provided to those randomised to CSII or RT-CGM. All participants will be provided with a Medtronic Veo insulin pump to enable use of the bolus prandial insulin dose wizard calculator whether or not they are administering insulin by CSII. All will be provided with a Contour link SMBG meter enabling direct transmission to the pump dose calculator. Access to Carelink glucose self-management software will also be provided to all participants to be used optionally to support attainment of study targets without any specific additional goals / training.

All participants (regardless of treatment arm) will attend an education session solely on the technical aspects of the insulin administration or glucose monitoring equipment they will be using during the intervention period, i.e. participants randomised to CSII will receive education restricted to technical aspects of insulin pump management including on the need to change the infusion set at least every $72 \mathrm{~h}$; participants randomised to MDI will receive education restricted to insulin device (pen) use and injection site care.

Participants randomised to RT-CGM will receive education restricted to the technical aspects of using the RT monitors including trend analysis and the use of the hypoglycaemia and hyperglycaemia alarms. They will be encouraged to wear the sensor continuously (re-siting every 7 days) but flexibly with a minimum of 7 days continuous monitoring in the last week of each month. Participants not randomised to RT-CGM will receive education restricted to the technical aspects of using the Contour link meter with the bolus calculator on the pump.

Participants will be seen one week after starting the study intervention to review progress over the first week, using glucose data to achieve the primary goal of avoiding biochemical hypoglycaemia.

\section{Study drugs and devices}

In accordance with the Medicines for Human Use (Clinical Trials) Regulations 2004 and Directive 2001/20/EC, the drugs under investigation in this trial fall under the definition of 'investigational medicinal product' (IMP). Although the insulins used during this trial fall under the definition of IMPs they will be used under existing licence.

\section{Insulin for MDI participants}

For the participants randomised to MDI, insulin aspart will be given as $3 \mathrm{ml}$ cartridge 100 Units/mL in a prefilled pen $\left(\right.$ Flexpen $\left.^{\circledR}\right)$. Insulin glargine will be given as $3 \mathrm{ml}$ cartridge 100 Units $/ \mathrm{mL}$ in a pre-filled pen $\left(\right.$ SoloStar $\left.^{\circledR}\right)$. However, for those participants who have had a previous negative experience or adverse effect with insulin aspart, insulin lispro will be offered as $3 \mathrm{ml}$ cartridge 100 Units $/ \mathrm{mL}$ in a pre-filled pen $\left(\right.$ Kwikpen $\left.^{\circledR}\right)$.

\section{Insulin for CSII participants}

For participants randomised to CSII, insulin aspart will be the insulin used as $10 \mathrm{ml}$ vial 100 Units/mL. Insulin lispro can be used instead of insulin aspart for those who have had previous negative experience / adverse effects.

\section{Insulin pumps}

All participants will be given an insulin pump that can receive and display CGM data (Mini-Med Paradigm Veo insulin pump) and will be taught how to use the onboard bolus calculator. Only those randomised to CSII will use the pump for insulin administration, the MDI groups will only use the bolus calculator feature and, if randomised to RT-CGM, the CGM feature. All participants randomised to CSII (insulin pump therapy) will be given a single additional session restricted to technical aspects of pump management.

\section{Self Monitoring of Blood Glucose (SMBG)}

All participants will be required to undertake daily 4point and weekly 8-point self-monitored capillary glucose profiles. All participants will use the Contour link ${ }^{\circledR}$, Bayer Healthcare meter and will undertake this whether or not concurrent RT-CGM is being used. 


\section{Real time-continuous glucose monitoring}

Fifty per cent of all participants will be randomised to real time monitoring, using the CE-marked REAL time continuous glucose monitor (Medtronic).

\section{Advice on interpretation and action from SMBG / RTCGM}

All participants will attend an education session on the recording of SMBG but, for those participants randomised to RT-CGM, this session will also include the technical aspects of using the monitor. This includes trend analysis, hypoglycaemia and hyperglycaemia alarms. Participants will be given written instructions on how to use the data provided by continuous glucose monitors to make real-time adjustments of insulin doses and on the use of computer software (for those with a home computer) to retrospectively review the glucose data to alter future insulin doses. Participants randomised to RT-CGM will be encouraged to wear the sensor continuously but flexibly with a minimum of 7 days continuous monitoring in the final week of each month. Those participants randomised to RT-CGM will be advised to re-site the sensor every 7 days.

\section{Blinded continuous glucose monitors}

Blinded CGM will be undertaken using the CE-marked Medtronic wireless iPro system. These will be used in the 4-week wash in period and during the last seven days of every month. The patients and investigators are blinded to all of this data until the end of the primary 24 week RCT.

\section{Insulin titration protocol}

The blood glucose targets (for all patients in CSII and MDI groups) will be as follows:

Fasting blood glucose (FBG): 5.0 - $7.0 \mathrm{mmol} / \mathrm{l}$.

Pre-prandial blood glucose: $4.5-7.0 \mathrm{mmol} / \mathrm{l}$.

Post-prandial glucose*: $6.0-8.0 \mathrm{mmol} / \mathrm{l}$.

Bedtime blood glucose ${ }^{* * *}: 6.0-8.0 \mathrm{mmol} / \mathrm{l}$.

4 am blood glucose: $5.0-7.0 \mathrm{mmol} / \mathrm{l}$.

"postprandial blood glucose: measurement made $2 \mathrm{~h}$ after the start of a meal.

**bedtime blood glucose: measurement made within $30 \mathrm{~min}$ of retiring to bed for the night.

\section{Glargine titration in MDI group}

Insulin glargine will be self-administered and the following titration protocol will be followed:

- Take within 30 min of retiring to bed for night / no need for snack.

- Aim for stable (not falling) glucose through the night.
- Reduce dose if any hypoglycaemic episodes or glucose $<5.0 \mathrm{mmol} / \mathrm{l}$ between $4 \mathrm{~m}$ and before breakfast.

- Target glucose of 5-7 mmol/l before breakfastadjust dose by $1-2$ units to maintain target if necessary with primary aim being absolute avoidance of BH (Biochemical Hypoglycaemia).

- During periods of illness, basal insulin doses may need to be altered and this will be guided by SMBG levels.

\section{Introduction of twice daily glargine}

Participants randomised to MDI already on twice daily glargine will continue on this from the outset of the RCT. In other MDI participants, if glucose is consistently $>7 \mathrm{mmol} / \mathrm{l}$ before evening meal or highly variable between breakfast and evening meal, add second dose of insulin glargine before breakfast. Initial dose will be 4 units but can be adjusted in light of participant's current insulin doses. If glucose has been falling through the night, a 2-4 unit reduction in evening glargine dose will be actioned before bed on the day of commencing the morning dose. The addition of a second daily glargine dose will be considered for all participants in the MDI group. This can be initiated between study visits if necessary, e.g. after telephone advice.

Morning insulin glargine will be self-administered and adjusted as follows:

- Take within 30 min of rising from bed for the morning.

- Aim for stable (not falling) glucose through the afternoon.

- Reduce dose if any hypoglycaemic episodes or glucose $<5 \mathrm{mmol} / \mathrm{l}$ between $2 \mathrm{~h}$ after lunch and evening meal.

- Target glucose of 5-7 mmol/l before evening meal adjust dose by $1-2$ units to maintain target if necessary with primary aim being absolute avoidance of $\mathrm{BH}$.

\section{Basal insulin titration in CSII group}

The basal insulin delivery rate will be titrated according to fasting, bedtime, pre-prandial and 4 am glucose levels ensuring absence of recurrent low glucose levels at these times (checkpoints). Increased or decreased delivery will be commenced from the previous basal insulin checkpoint level, i.e. if low at 4 am-decrease from bedtime; if high fasting increase from $4 \mathrm{am}$.

Mean fasting; bedtime; 4 am and pre-prandial blood glucose:

- Within target: No change to basal delivery rate.

- Above target: Increase basal insulin by $0.1 \mathrm{U} / \mathrm{hr}$ from previous check point. 
- Below target or unexplained late post-prandial hypoglycaemia: Decrease basal insulin by $0.1 \mathrm{U} / \mathrm{hr}$ from previous check point.

During periods of illness, basal insulin rates may need to be altered and this will be guided by SMBG levels.

\section{Meal-time insulin bolus in all groups (CSII and MDI)}

Carbohydrate counting skills and bolus dose adjustment in light of current blood glucose level / individualised insulin carbohydrate ratios will be reviewed in all participants. Aspart or lispro will be delivered either by subcutaneous injection or as a subcutaneous pump bolus before all meals and snacks with substantial carbohydrate content.

Insulin: carbohydrate ratios will be calculated for all individuals using the ' 500 rule' and using total daily insulin doses pre-randomisation. The ' 500 rule' is:

500 divided by the TDD (Total Daily Dose of insulin) = grams of carbohydrate covered by one unit of aspart or lispro.

In the event of high pre-prandial glucose levels corrective doses will also be recommended with meals as part of the meal time bolus. This will be calculated using the '100 rule' for estimation of Insulin Sensitivity Factor. The ' 100 rule' is:

100 divided by the TDD (Total daily Dose of insulin) = glucose drop in mmol/l per 1 unit of aspart or lispro.

This will be presented to all participants as ' 1 unit of aspart / lispro will reduce your blood glucose by $x$ mmol/l'.

Corrective doses with all pre-main meal boluses / prandial insulin injections will be encouraged according to the 100 rule when glucose level is above target.

The insulin: carbohydrate ratio and Insulin Sensitivity Factor for that period of the day will be adjusted accordingly in the event that:

- The glucose level is consistently below or above target $2 \mathrm{~h}$ after a bolus / prandial insulin injection.

- If any unexplained hypoglycaemic event occurs $2 \mathrm{~h}$ after a bolus / prandial insulin injection.

\section{Telephone contact}

Participants will be contacted by telephone daily for the first week after starting the study intervention and thereafter weekly throughout the RCT to reinforce the primary goal of $\mathrm{BH}$ avoidance, provide clinical review / support, and ensure diary completion.

\section{Study follow up}

Participants will attend for a study visit every four weeks during the RCT for collection of SMBG/hypoglycaemia diary and HbAlc. One week prior to each visit participants will have a blinded CGM device fitted and these data will be downloaded at the visit. Participants will have their weight measured at each follow up visit and this, along with details of insulin dosage, will be recorded on visit specific CRFs. Both investigator and participant will remain blinded to the results of the blinded CGM data during the RCT period. Clinical review at each follow up visit will reinforce the primary goal of $\mathrm{BH}$ avoidance. At each follow up visit information will be collected on any episodes of hypoglycaemia experienced, duration of RT-CGM monitoring usage and RT-CGM alarm settings.

At week 24, participants will attend for the primary RCT completion visit. This will include blinded CGMS data download, collection of SMBG/hypoglycaemia diary, and HbA1c. Participants will also be asked to complete the 'end of RCT' study-specific questionnaire booklets assessing hypoglycaemia experience and other PROs (Table 2).

On the same day, participants will be invited to attend for 'end of RCT' stepped hyperinsulinaemic hypoglycaemic clamp as described below.

At the end of this intervention period, participants will be asked to attend for repeat detailed cardiac autonomic function testing and subjective assessment of global autonomic symptoms.

\section{Post primary RCT follow-up}

At the end of the 24-week RCT, participants will return to routine clinical care. Those randomised to CSII may stop this if they and their clinical team wish. Commencement of CSII according to NICE guidance [34] will be considered in those previously randomised to MDI. Those participants who were randomised to RT-CGM will continue with this intervention for a further 18 months constituting an overall 24 month RCT of RT-CGM augmented glucose monitoring vs SMBG alone. RT-CGM will not be offered to those not randomised to this intervention, as it is not currently recommended by NICE. All participants will be invited to attend three follow-up visits 6,12 and 18 months post primary RCT (Table 1). Participants will be fitted with a blinded CGM device for 7 days before each followup visit. This visit will include collection of SMBG/ hypoglycaemia diary; SMBG / CGM data download, HbA1c measurement. Participants will be required to complete questionnaire booklets (Table 2) at each follow-up visit.

The end of the study will be the last follow-up visit of the last participant scheduled for 24 months after the commencement of study interventions. 


\section{Hypoglycaemic clamp study}

A stepped hyperinsulinaemic hypoglycaemic clamp study [49] will be conducted in participants who are willing to undergo this procedure for which separate informed consent will be obtained. It is envisaged that approximately $25 \%$ of participants will be studied. Additional exclusion criteria will be in place to ensure participant safety:

- Age $>60$ years.

- History of epilepsy (seizures not primarily induced by hypoglycaemia).

- Known ischaemic heart disease.

- Other significant disease which in the judgement of the investigator precludes participation.

Participants will be fitted with a retrospective CGM sensor to be worn typically for five to seven days (at least $24 \mathrm{~h}$ ) preceding the study day. This will be downloaded on the morning of the study to determine whether any antecedent biochemical hypoglycaemia (BH) occurred over the $24 \mathrm{~h}$ period prior to the clamp. Studies will be postponed to another day if any CGM and/or selfmonitored capillary glucose below $3.0 \mathrm{mmol} / \mathrm{l}$ are detected during the preceding $24 \mathrm{~h}$. For participants who required rescheduling, a further $72 \mathrm{~h}$ of CGM will be organised. All participants will be advised to fast from 22:00 $\mathrm{h}$ and to avoid caffeine for $24 \mathrm{~h}$ before the study.

The participant will be admitted to the clinical research facility at 7 am on the day of the study. On arrival, an intravenous cannula will be inserted in the ante-cubital vein of the non-dominant arm and blood glucose will be stabilized using sliding scale insulin infusion aiming initially for blood glucose $6.0-7.0 \mathrm{mmol} / \mathrm{l}$ and then 5.0-6.0 mmol/l between $10.30 \mathrm{am}$ and $11 \mathrm{am}$ for clamp initiation.

A second retrograde cannula will be inserted into a vein on the dorsum of the non-dominant hand for the sampling of arterialised venous blood. The hand will be kept in a purpose-built heated box (Temp $50-60^{\circ}$ Celsius) before inserting the retrograde cannula and throughout the clamp study. A slow intravenous infusion of saline will be used as needed to keep the sampling line patent. During this period of stabilization, participants will be shown how to perform specific cognitive function tests (Four choice reaction time [50-52] and Stroop tests $[53,54])$ and asked to practise the tests until they achieve consistent results (typically 5 practice sessions). Fourchoice reaction time is a test of attention, discrimination and motor speed reaction while Stroop tests are a group of related sub-tests all requiring selective attention and mental tracking.

At the start of the clamp a primed infusion of $60 \mathrm{mU} /$ $\mathrm{m}^{2} / \mathrm{min}$ soluble human Actrapid insulin will be started via the non-dominant antecubital vein catheter. Dextrose infusion rates will be adjusted as needed, aiming to stabilise plasma glucose at $5.0 \mathrm{mmol} / \mathrm{l}$ at $40 \mathrm{mins}$ followed by step-wise lowering to $3.8 \mathrm{mmol} / \mathrm{l}, 3.4 \mathrm{mmol} / \mathrm{l} 2.8 \mathrm{mmol} / \mathrm{l}$ and $2.4 \mathrm{mmol} / \mathrm{l}$. Each step will last $40 \mathrm{~min}$ allowing $20 \mathrm{~min}$ to achieve new target and $20 \mathrm{~min}$ for stabilization at that level. Samples for plasma glucose will be obtained every $5 \mathrm{~min}$ and analysed in real-time but participants will be blinded to these glucose levels throughout the study.

At the end of each clamp stage participants will be asked to complete a validated symptom questionnaire $[55,56]$ followed by the four choice reaction time test and Stroop test. Each symptom will be graded on a visual analogue scale from 1 (not at all) to 7 (very severe).

Arterialised venous blood samples for insulin, catecholamines, growth hormones, glucagon and cortisol will be obtained every $10 \mathrm{~min}$ during the first $40 \mathrm{~min}$ of the study (euglycaemia) followed by every $20 \mathrm{~min}$ during progressive hypoglycaemia. Heart rate and blood pressure will be recorded every $20 \mathrm{~min}$. In addition, spectral analysis of heart rate variability and assessment of cardiac vagal baroreflex sensitivity (BRS) will be carried out during each clamp stage. At the end of the study, insulin infusion will be reduced to basal insulin requirements and dextrose infusion increased to raise blood glucose to euglycaemia. Participants will be provided with lunch with post-meal insulin bolus and re-established on their usual insulin regimen thereafter.

\section{Sample size}

The recruitment target for the overall RCT is $n=100$ participants $(\mathrm{n}=20$ from each of the five participating centres). From the pilot study data [41], the sample size of $n=100$ ( $n=25$ in each of the four study arms) would give $80 \%$ power at a significance level of 0.05 to detect a difference of 1.1 between the IAH scores (assessed using the Gold Score) of the 50 participants randomised to either of the CSII arms and the 50 randomised to either of the MDI arms. A difference of at least one point (on the 7-point scale) is considered to be a clinically relevant change on the Gold Score. The calculation is based on the use of the 2-sample t-test and the assumption, taken from the pilot data, that the standard deviation of the IAH score is 2 (mean \pm SD Gold Score in the pilot study was $2.57 \pm 1.90$ in the CSII arm and $4.0 \pm 1.79$ in the MDI arm).

\section{Outcomes / statistical analysis}

The principal analysis will examine the factorial structure of the treatment and monitoring regimen effects on the difference in IAH (Gold score) at 24 weeks using analysis of covariance (ANCOVA). Baseline IAH (Gold score) and stratification (centre and baseline HbA1c) variables will be included among the covariates to be considered in addition to suitable summaries of 
questionnaire scores and glucose monitoring data collected at baseline prior to randomisation. The glucose monitoring data to be collected include time spent for the following separate ranges: $<2.5 \mathrm{mmol} / \mathrm{l},<3 \mathrm{mmol} / \mathrm{l}$, $<4 \mathrm{mmol} / \mathrm{l},>7 \mathrm{mmol} / \mathrm{l},>10 \mathrm{mmol} / \mathrm{l}$, between 4 and $7 \mathrm{mmol} / \mathrm{l}$ and between 3 and $10 \mathrm{mmol} / \mathrm{l}$. The inclusion of baseline HbA1c as a covariate will enable the examination of possible interactions between effects observed and these values.

Further analyses will be undertaken concerning IAH to corroborate the Gold Score; the Gold Score will be compared with scale and subscale scores derived from the Clarke Questionnaire and the Hypoglycaemia Awareness Questionnaire (HypoA-Q) at 24 weeks.

These measures will also be subject to analysis as for the primary outcome. Additionally, a binary indicator of IAH response (defined as a Gold Score of $<4$ or $\geq 4$ ) at 24 weeks will be analysed using logistic regression making use of the covariates used for the primary outcome analysis.

There will also be an additional analysis of the (paired) change in IAH (Gold Score) over the 24-week duration of the trial using the t-test without consideration of the intervention or monitoring groups in order to evaluate the effect of undergoing any intervention or monitoring over the 24-week period.

Other outcomes will be assessed at baseline and 24 weeks. Analysis methods will generally be similar to that described for the primary analysis but alternative techniques such as McNemar's test and logistic regression will be used as appropriate.

Further analyses will be undertaken using HbA1c and the separate continuous glucose monitoring measures (time spent in the following separate ranges: $<2.5 \mathrm{mmol} / \mathrm{l}$, $<3 \mathrm{mmol} / \mathrm{l},<4 \mathrm{mmol} / \mathrm{l},>7 \mathrm{mmol} / \mathrm{l},>10 \mathrm{mmol} / \mathrm{l}$, between 4 and $7 \mathrm{mmol} / \mathrm{l}$ and between 3 and $10 \mathrm{mmol} / \mathrm{l}$ ) as outcome variables.

Similar analyses will be undertaken on scores from all PRO measure scores used in the study (Table 2).

A number of measures relating to SH (ADA criteria) will be analysed: number of episodes of $\mathrm{SH}$ at 24 weeks, change in $\mathrm{SH}$ between baseline and 24 weeks (reported as difference in annualised rate pre and post-intervention), change in $\mathrm{SH}$ between baseline and 24 weeks (reported as the proportion of participants with reduction in number of $\mathrm{SH}$ events compared between the timepoints) and change in proportion without $\mathrm{SH}$ between baseline and 24 weeks.

Changes in weight, total daily dose of insulin, and in glucose lability will be subject to analysis in a similar manner to the primary outcome.

Wherever possible participants who elect to withdraw from the study will be followed up so that final outcome data are obtained, enabling their inclusion in an Intention to Treat (ITT) analyses. This will form the analysis groups for the analyses described above.

Analyses restricted to those participants who were allocated to use RT-CGM will be considered, in order to allow use of the further covariate of low or high CGM use (defined by consideration of a pre-defined cut-off value) throughout the 24-week period. Variables analysed in this manner will include IAH (Gold Score), episodes of SH, HbA1c and several of the glucose monitoring measures.

Variables with missing data will be examined and the amount of missing data described. Data analysis will take the form of a complete case analysis, although imputation of values may be considered for the primary outcome variable alone should this be missing to a sufficient extent.

Significance levels will be set at $\alpha=0.05$ throughout.

Safety data are to be documented but will not be subject to statistical analysis.

A detailed analysis plan will be finalised prior to the commencement of data analysis.

Data from the clamp study will be analysed separately; however a comparison will be made between the IAH (Gold) based definition of response and a response measure derived from the clamp results.

\section{Trial Governance}

Trial management will be overseen by a Trial Management Group who will meet regularly to discuss the operational aspects of the trial. An independent Data Monitoring and Ethics Committee (DMEC) will be convened to undertake independent review, monitoring safety and efficacy endpoints. The DMEC will comprise two physicians not connected to the trial (at least one of whom will have expertise in hypoglycaemia), one statistician and one patient representative. The DMEC will have full access to unblinded study data.

A Trial Steering Committee (TSC) will supervise the trial, ensuring it is conducted to high standards in accordance with the protocol, the principles of GCP, and with regard to participant safety. This committee will have an independent chair with expertise in hypoglycaemia. In addition to the Chief Investigator (Professor James Shaw) and Principal Investigators, the TSC will consist of a sponsor/funder representative, representatives of the Newcastle Clinical Trials Unit and two consumer representatives. The TSC will also consider safety issues for the trial and relevant information from other sources, ensuring at all times that ethical considerations are met when recommending the continuation of the trial.

\section{Discussion}

Over recent years, it has become increasingly clear that $\mathrm{SH}$ is the major factor limiting the overall level of 
glucose control achievable in those with established T1DM. We believe that this study will provide definitive evidence that recurrent $\mathrm{SH}$ is preventable even in the majority of those at highest risk. This will enable a truly evidence-based approach to improving day-to-day diabetes management for all those currently living with the risk and fear of $\mathrm{SH}$. In addition, characteristics of the minority in whom optimised conventional therapy is likely to prove inadequate will be defined, enabling early identification and intervention.

While the interventions in this trial are widely used in an attempt to reduce the incidence of $\mathrm{SH}$, there is little evidence from adequately powered RCTs supporting their use, with most existing RCTs having been powered for change in glycated haemoglobin rather than SH or IAH. The primary objective of this trial is to determine whether these treatments improve awareness of hypoglycaemia and, secondarily, to determine whether they have an impact on SH events and overall glycaemic control. Crucially, this unique trial will also determine the impact of these intensive interventions on a range of patient-reported outcomes.

The trial does pose challenges, perhaps foremost the need to ensure equal input to all study participants and not provide additional care to those randomised to pump therapy. The protocol was designed to take this into consideration. Participants randomised to MDI will also be provided with insulin pumps so that this group is not disadvantaged by not having access to a bolus calculator. Secondly, study investigators will need to remain absolutely focused on biochemical hypoglycaemia avoidance, undiluted by attempts to tighten or maintain overall glycaemic control. This may be made more challenging by existing investigator and participant behaviours. For this reason, detailed insulin titration protocols (detailed above) will be used across all sites.

This ambitious and intensive trial will demonstrate definitively whether $\mathrm{SH}$, a cause of major morbidity in up to 5000 adults with T1DM in the UK, can be prevented successfully in even those at highest risk by optimised conventional management using existing technology. Overall biomedical, psychosocial and health utility impact of MDI, CSII and RT in this group will be determined employing optimised measures as detailed above.

\footnotetext{
Competing interests

No pharmaceutical company or medical device manufacturer has had any role in the design or funding of this trial.

DK has received honoraria for participation in educational events and consultancy fees from Abbott Diabetes Care, manufacturers of glucose sensors. JAMS has in the past taken part in Medical Advisory Boards for Novo Nordisk, Sanofi Aventis, Johnson and Johnson and Medtronic.

JSp is a member of the Accu-Chek Advisory Board. In relation to this activity, JSp's research group, The Australian Centre for Behavioural Research in Diabetes, has received consultancy fees from Roche Diagnostics Australia. It is also the recipient of unrestricted educational grants from Sanofi Aventis and Medtronic, and speaker fees from Abbott Diabetes Care.
}

PC has received speaker fees and been on Advisory Boards for Medtronic, Johnson and Johnson and Roche.

ME has acted on Advisory Boards for Medtronic, Roche and Cellnovo and received travel support/speakers fees from Medtronic and Animas.

SH has carried out consultancy work for pump/meter, insulin companies, Lifescan, Sanofi-Aventis, NovoNordisk and Lilly. Medtronic has supplied pumps for use in one of his studies.

\section{Authors' contribution}

JAMS, JSP, DK, PC, SH, ME, DF, TO, RT, SMM and SB conceived the study and participated in its design. TC advised on the statistical analysis plan. SL, LL, HKT and EW have responsibility regarding the clinical management of the participants and helped to draft the manuscript. CB and JSt participated in the study design and coordination. All authors read and approved the final manuscript.

\section{Acknowledgements}

We thank Prof B Frier, University of Edinburgh for his advice and experience in planning this study. We also thank Prof J Matthews, Newcastle University for his advice on the statistical analysis plan. The study is funded by a peerreviewed grant from Diabetes UK.

\section{Author details}

${ }^{1}$ Institute of Cellular Medicine, The Medical School, Newcastle University, 4th Floor William Leech Building, Framlington Place, Newcastle upon Tyne NE2 $4 \mathrm{HH}, \mathrm{UK} .{ }^{2}$ Institute of Health and Society, Newcastle University, Newcastle, UK. ${ }^{3}$ Diabetes and Nutritional Sciences Division, Kings College London, London, UK. ${ }^{4}$ AHP Research, Hornchurch, UK. 'Bournemouth Diabetes Centre, Bournemouth, UK. ${ }^{6}$ Institute of Metabolic Science, University of Cambridge, Cambridge, UK. ${ }^{7}$ School of Medicine and Biomedical Sciences, Sheffield University, Sheffield, UK. ${ }^{8}$ Peninsula College of Medicine and Dentistry, Plymouth, UK. ${ }^{9}$ The Australian Centre for Behavioural Research in Diabetes, Diabetes Australia - Vic, Melbourne, Australia. ${ }^{10}$ Centre for Mental Health and Wellbeing Research, School of Psychology, Deakin University, Burwood, Australia.

Received: 27 October 2012 Accepted: 19 November 2012

Published: 13 December 2012

\section{References}

1. Forouhi NG, Merrick D, Goyder E, Ferguson BA, Abbas J, Lachowycz K: Diabetes prevalence in England, 2001-estimates from an epidemiological model. Diabet Med 2006, 23(2):189-197. PubMed PMID: 16433718. Epub 2006/01/26. eng.

2. The Diabetes Control and Complications Trial Research Group: The effect of intensive treatment of diabetes on the development and progression of long-term complications in insulin-dependent diabetes mellitus. The Diabetes Control and Complications Trial Research Group. N Engl J Med 1993, 329(14):977-986. PubMed PMID: 8366922. Epub 1993/09/30. eng.

3. The Writing Team for the Diabetes Control and Complications Trial/ Epidemiology of Diabetes Interventions and Complications Research Group: Sustained effect of intensive treatment of type 1 diabetes mellitus on development and progression of diabetic nephropathy: the Epidemiology of Diabetes Interventions and Complications (EDIC) study. JAMA 2003, 290(16):2159-2167. PubMed PMID: 14570951. Pubmed Central PMCID: 2622725. Epub 2003/10/23. eng.

4. Cryer PE: Hypoglycaemia: the limiting factor in the glycaemic management of Type I and Type II diabetes. Diabetologia 2002, 45(7):937-948. PubMed PMID: 12136392. Epub 2002/07/24. eng.

5. Pedersen-Bjergaard U, Pramming S, Heller SR, Wallace TM, Rasmussen AK, Jorgensen HV, et al: Severe hypoglycaemia in 1076 adult patients with type 1 diabetes: influence of risk markers and selection. Diabetes Metab Res Rev 2004, 20(6):479-486. PubMed PMID: 15386817. Epub 2004/09/24. eng.

6. Tattersall RB, Gill GV: Unexplained Deaths of Type-1 Diabetic-Patients. Diabet Med 1991, 8(1):49-58. PubMed PMID: ISI:A1991ET26600010. English.

7. Cryer PE, Davis SN, Shamoon H: Hypoglycemia in diabetes. Diabetes Care 2003, 26(6):1902-1912. PubMed PMID: 12766131. Epub 2003/05/27. eng.

8. DCCT: Epidemiology of severe hypoglycemia in the diabetes control and complications trial. The DCCT Research Group. Am J Med 1991, 90(4): 450-459. PubMed PMID: 2012085. Epub 1991/04/01. eng. 
9. Geddes J, Wright RJ, Zammitt NN, Deary IJ, Frier BM: Diabetes Care 2007, 30(7):1868-1870. PubMed PMID: 17416785. Epub 2007/04/10. eng.

10. Geddes J, Schopman JE, Zammitt NN, Frier BM: Prevalence of impaired awareness of hypoglycaemia in adults with Type 1 diabetes. Diabet Med 2008, 25(4):501-504.

11. Gold AE, MacLeod KM, Frier BM: Frequency of severe hypoglycemia in patients with type I diabetes with impaired awareness of hypoglycemia. Diabetes Care 1994, 17(7):697-703. PubMed PMID: 7924780. Epub 1994/07/01. eng

12. Veneman T, Mitrakou A, Mokan M, Cryer P, Gerich J: Induction of hypoglycemia unawareness by asymptomatic nocturnal hypoglycemia. Diabetes 1993, 42(9):1233-1237. PubMed PMID: 8349033. Epub 1993/09/01. eng.

13. Mitrakou A, Fanelli C, Veneman T, Perriello G, Calderone S, Platanisiotis D, et al: Reversibility of unawareness of hypoglycemia in patients with insulinomas. N Engl J Med 1993, 329(12):834-839. PubMed PMID: 8355741. Epub 1993/09/16. eng.

14. Fanelli CG, Epifano L, Rambotti AM, Pampanelli S, Di Vincenzo A, Modarelli $F$, et al: Meticulous prevention of hypoglycemia normalizes the glycemic thresholds and magnitude of most of neuroendocrine responses to, symptoms of, and cognitive function during hypoglycemia in intensively treated patients with short-term IDDM. Diabetes 1993, 42(11):1683-1689. PubMed PMID: 8405713. Epub 1993/11/01. eng.

15. Cranston I, Lomas J, Maran A, Macdonald I, Amiel SA: Restoration of hypoglycaemia awareness in patients with long-duration insulindependent diabetes. Lancet 1994, 344(8918):283-287. PubMed PMID: 7914259. Epub 1994/07/30. eng.

16. Gale EA: A randomized, controlled trial comparing insulin lispro with human soluble insulin in patients with Type 1 diabetes on intensified insulin therapy. The UK Trial Group. Diabet Med 2000, 17(3):209-214. PubMed PMID: 10784225. Epub 2000/04/28. eng.

17. Heller SR, Amiel SA, Mansell P: Effect of the fast-acting insulin analog lispro on the risk of nocturnal hypoglycemia during intensified insulin therapy. U.K. Lispro Study Group. Diabetes Care 1999, 22(10):1607-1611. PubMed PMID: 10526722. Epub 1999/10/20. eng.

18. Holleman F, Schmitt H, Rottiers R, Rees A, Symanowski S, Anderson JH: Reduced frequency of severe hypoglycemia and coma in well-controlled IDDM patients treated with insulin lispro. The Benelux-UK Insulin Lispro Study Group. Diabetes Care 1997, 20(12):1827-1832. PubMed PMID: 9405901. Epub 1997/12/24. eng.

19. Ratner RE, Hirsch IB, Neifing JL, Garg SK, Mecca TE, Wilson CA: Less hypoglycemia with insulin glargine in intensive insulin therapy for type 1 diabetes. U.S. Study Group of Insulin Glargine in Type 1 Diabetes. Diabetes Care 2000, 23(5):639-643. PubMed PMID: 10834423. Epub 2000/06/02. eng.

20. Pieber TR, Eugene-Jolchine I, Derobert E: Efficacy and safety of HOE 901 versus NPH insulin in patients with type 1 diabetes. The European Study Group of HOE 901 in type 1 diabetes. Diabetes Care 2000, 23(2):157-162. PubMed PMID: 10868824. Epub 2000/06/27. eng.

21. Fulcher GR, Gilbert RE, Yue DK: Glargine is superior to neutral protamine Hagedorn for improving glycated haemoglobin and fasting blood glucose levels during intensive insulin therapy. Intern Med J 2005, 35(9):536-542. PubMed PMID: 16105155. Epub 2005/08/18. eng.

22. Porcellati F, Rossetti P, Pampanelli S, Fanelli CG, Torlone E, Scionti L, et al: Better long-term glycaemic control with the basal insulin glargine as compared with NPH in patients with Type 1 diabetes mellitus given meal-time lispro insulin. Diabet Med 2004, 21(11):1213-1220. PubMed PMID: 15498088. Epub 2004/10/23. eng.

23. Rossetti P, Pampanelli S, Fanelli C, Porcellati F, Costa E, Torlone E, et al: Intensive replacement of basal insulin in patients with type 1 diabetes given rapid-acting insulin analog at mealtime: a 3-month comparison between administration of NPH insulin four times daily and glargine insulin at dinner or bedtime. Diabetes Care 2003, 26(5):1490-1496. PubMed PMID: 12716810. Epub 2003/04/30. eng.

24. De Leeuw I, Vague P, Selam JL, Skeie S, Lang H, Draeger E, et al: Insulin detemir used in basal-bolus therapy in people with type 1 diabetes is associated with a lower risk of nocturnal hypoglycaemia and less weight gain over 12 months in comparison to NPH insulin. Diabetes Obes Metab 2005, 7(1):73-82. PubMed PMID: 15642078. Epub 2005/01/12. eng.

25. Bartley PC, Bogoev M, Larsen J, Philotheou A: Long-term efficacy and safety of insulin detemir compared to Neutral Protamine Hagedorn insulin in patients with Type 1 diabetes using a treat-to-target basal-bolus regimen with insulin aspart at meals: a 2-year, randomized, controlled trial. Diabet Med 2008, 25(4):442-449. PubMed
PMID: 18387078. Pubmed Central PMCID: 2327220. Epub 2008/04/05. eng.

26. Kolendorf K, Ross GP, Pavlic-Renar I, Perriello G, Philotheou A, Jendle J, et al: Insulin detemir lowers the risk of hypoglycaemia and provides more consistent plasma glucose levels compared with NPH insulin in Type 1 diabetes. Diabet Med 2006, 23(7):729-735. PubMed PMID: 16842476. Epub 2006/07/18. eng.

27. Vague P, Selam JL, Skeie S, De Leeuw I, Elte JW, Haahr H, et al: Insulin detemir is associated with more predictable glycemic control and reduced risk of hypoglycemia than NPH insulin in patients with type 1 diabetes on a basal-bolus regimen with premeal insulin aspart. Diabetes Care 2003, 26(3):590-596. PubMed PMID: 12610006. Epub 2003/03/01.

28. National Institute for Clinical Excellence: Technology Appraisal No. 53. Guidance on the use of long-acting insulin analogues for the treatment of diabetes - insulin glargine. NICE; 2002. http://www.nice.org.uk/nicemedia/ live/11482/32518/32518.pdf.

29. Boland EA, Grey M, Oesterle A, Fredrickson L, Tamborlane W: Continuous subcutaneous insulin infusion. A new way to lower risk of severe hypoglycemia, improve metabolic control, and enhance coping in adolescents with type 1 diabetes. Diabetes Care 1999, 22(11):1779-1784. PubMed PMID: 10546007. Epub 1999/11/05. eng.

30. Doyle EA, Weinzimer SA, Steffen AT, Ahern JA, Vincent M, Tamborlane WV: A randomized, prospective trial comparing the efficacy of continuous subcutaneous insulin infusion with multiple daily injections using insulin glargine. Diabetes Care 2004, 27(7):1554-1558. PubMed PMID: 15220227. Epub 2004/06/29. eng.

31. Hirsch IB, Bode BW, Garg S, Lane WS, Sussman A, Hu P, et al: Continuous subcutaneous insulin infusion (CSII) of insulin aspart versus multiple daily injection of insulin aspart/insulin glargine in type 1 diabetic patients previously treated with CSII. Diabetes Care 2005, 28(3):533-538. PubMed PMID: 15735183. Epub 2005/03/01. eng.

32. Misso ML, Egberts KJ, Page M, O'Connor D, Shaw J: Continuous subcutaneous insulin infusion (CSII) versus multiple insulin injections for type 1 diabetes mellitus. Cochrane Database of Systematic Reviews 2010, (Issue 1):CD005103. doi:10.1002/14651858.CD005103.pub2.

33. Bode BW, Steed RD, Davidson PC: Reduction in severe hypoglycemia with long-term continuous subcutaneous insulin infusion in type I diabetes. Diabetes Care 1996, 19(4):324-327. PubMed PMID: 8729154. Epub 1996/04/01. eng.

34. National Institute for Health and Clinical Excellence NICE technology appraisal guidance 151: Continuous subcutaneous insulin infusion for the treatment of diabetes mellitus (review of technology appraisal guidance 57). NICE; 2008. http://guidance.nice.org.uk/TA151/Guidance/pdf/English.

35. Deiss D, Bolinder J, Riveline JP, Battelino T, Bosi E, Tubiana-Rufi N, et al: Improved glycemic control in poorly controlled patients with type 1 diabetes using real-time continuous glucose monitoring. Diabetes Care 2006, 29(12):2730-2732. PubMed PMID: 17130215. Epub 2006/11/30. eng.

36. Tamborlane WW, Beck RW, Bode BW, Buckingham B, Chase HP, Clemons R, et al: Continuous glucose monitoring and intensive treatment of type 1 diabetes. N Engl J Med 2008, 359(14):1464-1476. PubMed PMID: 18779236. Epub 2008/09/10. eng.

37. Bergenstal RM, Tamborlane WV, Ahmann A, Buse JB, Dailey G, Davis SN, et al: Effectiveness of sensor-augmented insulin-pump therapy in type 1 diabetes. N Engl J Med 2010, 363(4):311-320. PubMed PMID: 20587585. Epub 2010/07/01. eng.

38. Hermanides J, Nørgaard K, Bruttomesso D, Mathieu C, Frid A, Dayan C, et al: Sensor augmented pump therapy substantially lowers $\mathrm{HbA1c}$; a randomized controlled trial. Diabetologia 2009, 52(Suppl 1):S43. Abstract.

39. Battelino T, Phillip M, Bratina N, Nimri R, Oskarsson P, Bolinder J: Effect of continuous glucose monitoring on hypoglycemia in type 1 diabetes. Diabetes Care 2011, 34(4):795-800. PubMed PMID: 21335621. Pubmed Central PMCID: 3064030. Epub 2011/02/22. eng.

40. Davis RE, Morrissey M, Peters JR, Wittrup-Jensen K, Kennedy-Martin T, Currie $\mathrm{CJ}$ : Impact of hypoglycaemia on quality of life and productivity in type 1 and type 2 diabetes. Curr Med Res Opin 2005, 21(9):1477-1483. PubMed PMID: 16197667. Epub 2005/10/04. eng.

41. Thomas RM, Aldibbiat A, Griffin W, Cox MA, Leech NJ, Shaw JA: A randomized pilot study in Type 1 diabetes complicated by severe hypoglycaemia, comparing rigorous hypoglycaemia avoidance with insulin analogue therapy, CSII or education alone. Diabet Med 2007, 24(7):778-783. PubMed PMID: 17535290. Epub 2007/05/31. eng. 
42. Clarke WL, Cox DJ, Gonder-Frederick LA, Julian D, Schlundt D, Polonsky W: Reduced awareness of hypoglycemia in adults with IDDM. A prospective study of hypoglycemic frequency and associated symptoms. Diabetes Care 1995, 18(4):517-522. PubMed PMID: 7497862. Epub 1995/04/01. eng.

43. Moher D, Schulz KF, Altman DG: The CONSORT statement: revised recommendations for improving the quality of reports of parallel-group randomised trials. Lancet 2001, 357(9263):1191-1194. PubMed PMID: 11323066. Epub 2001/04/27. eng.

44. Diagnosis and classification of diabetes mellitus. Diabetes Care 2011, 34(Suppl 1):S62-S69. PubMed PMID: 21193628. Pubmed Central PMCID: 3006051. Epub 2011/01/14. eng.

45. World Health Organisation: Definition and diagnosis of diabetes mellitus and intermediate hyperglycemia: report of a WHO/IDF consultation. WHO; 2006. http://whqlibdoc.who.int/publications/2006/9241594934_eng.pdf.

46. Tesfaye S, Boulton AJ, Dyck PJ, Freeman R, Horowitz M, Kempler P, et al: Diabetic neuropathies: update on definitions, diagnostic criteria, estimation of severity, and treatments. Diabetes Care 2010, 33(10): 2285-2293. PubMed PMID: 20876709. Pubmed Central PMCID: 2945176.

47. Suarez GA, Opfer-Gehrking TL, Offord KP, Atkinson EJ, O'Brien PC, Low PA: The Autonomic Symptom Profile: a new instrument to assess autonomic symptoms. Neurology 1999, 52(3):523-528. PubMed PMID: 10025781. Epub 1999/02/20. eng.

48. Cox D, Ritterband L, Magee J, Clarke W, Gonder-Frederick L: Blood glucose awareness training delivered over the internet. Diabetes Care 2008, 31(8):1527-1528. PubMed PMID: 18477813. Pubmed Central PMCID: 2494647. Epub 2008/05/15. eng.

49. Roden M: Clinical Diabetes Research: Methods and Techniques; Chapter 4 Glucose Clamp Techniques and Chapter 5 Methods of Assessment of Counterregulation to Hypoglycaemia. 1st edition. Wiley-Blackwell; 200720 July 2007.

50. Cranston I, Lomas J, Maran A, Macdonald I, Amiel SA: Restoration of hypoglycaemia awareness in patients with long-duration insulin-dependent diabetes. Lancet 1994, 344(8918):283-287. PubMed PMID: 7914259. eng.

51. Maran A, Lomas J, Macdonald IA, Amiel SA: Lack of preservation of higher brain function during hypoglycaemia in patients with intensively-treated IDDM. Diabetologia 1995, 38(12):1412-1418. PubMed PMID: 8786014. eng.

52. Heller SR, Macdonald IA: The measurement of cognitive function during acute hypoglycaemia experimental limitations and their effect on the study of hypoglycaemia unawareness. Diabet Med 1996, 13(7):607-615. PubMed PMID: ISI:A1996UZ37800003. English.

53. Lezak MD: Orientation and Attention. In Neuropsychological Assessment. 3rd edition. Oxford: Oxford University Press; 1995. Chapter 9.

54. Bench CJ, Frith CD, Grasby PM, Friston KJ, Paulesu E, Frackowiak RSJ, et al: Investigations of the Functional-Anatomy of Attention Using the Stroop Test. Neuropsychologia 1993, 31(9):907-922. PubMed PMID: ISI: A1993LZ62000003. English.

55. McAulay V, Deary IJ, Frier BM: Symptoms of hypoglycaemia in people with diabetes. Diabet Med 2001, 18(9):690-705. PubMed PMID: 11606166. Epub 2001/10/19. eng.

56. Deary IJ, Hepburn DA, MacLeod KM, Frier BM: Partitioning the symptoms of hypoglycaemia using multi-sample confirmatory factor analysis. Diabetologia 1993, 36(8):771-777. PubMed PMID: 8405746. Epub 1993/08/01. eng.

57. Bradley C, Lewis KS: Measures of psychological well-being and treatment satisfaction developed from the responses of people with tablet-treated diabetes. Diabet Med 1990, 7(5):445-51. Epub 1990/06/01.

58. Anderson RT, Skovlund SE, Marrero D, Levine DW, Meadows K, Brod M, et al: Development and validation of the insulin treatment satisfaction questionnaire. Clin Ther 2004, 26(4):565-Epub 2004/06/11.

59. The EuroQol Group: EuroQol-a new facility for the measurement of healthrelated quality of life. Health Policy 1990, 16(3):199-208. Epub 1990/11/05.

60. Bradley C, Brewin CR, Gamsu DS, Moses JL: Development of scales to measure perceived control of diabetes mellitus and diabetes-related health beliefs. Diabet Med 1984, 1(3):213-8. Epub 1984/09/01.

doi:10.1186/1472-6823-12-33

Cite this article as: Little et al:: Comparison of Optimised MDI versus Pumps with or without Sensors in Severe Hypoglycaemia (the Hypo COMPaSS trial). BMC Endocrine Disorders 2012 12:33.

\section{Submit your next manuscript to BioMed Central and take full advantage of:}

- Convenient online submission

- Thorough peer review

- No space constraints or color figure charges

- Immediate publication on acceptance

- Inclusion in PubMed, CAS, Scopus and Google Scholar

- Research which is freely available for redistribution 